\title{
Sensory changes and preservation with age: Hope for the undernourished
}

\author{
C. Withers ${ }^{*}{ }^{1}$, M. Dermiki ${ }^{1}$, M. A. Gosney ${ }^{2}$, R. Crabtree $^{1}$, O. B. Kennedy ${ }^{1}$, L. Methven ${ }^{1}$ \\ ${ }^{1}$ Department of Food and Nutritional Sciences, University of Reading, UK $;^{2}$ Clinical Health Sciences, \\ University of Reading, UK
}

Undernutrition affects around $32 \%$ of adults aged over $65^{[1]}$. In 2007,239 patients died of undernutrition, a condition that is badly underreported in hospitals and care homes ${ }^{[2]}$. Reduced food consumption could relate to changes in sensory perception with age ${ }^{[3]}$. Frequent attempts have been made to enhance food products for older adult groups ${ }^{[4-7]}$, however understanding age-related effects taste, olfaction, flavour and texture perception would provide insight into enhancing older patient nutrition. In a series of investigations, detection thresholds, discrimination thresholds and just-about-right tests, were used to understand age-related sensory changes. This study investigated the perception of basic tastes, ortho- and retro-nasal flavour perception and mouth-feel characteristics in healthy older and younger adults.

Older adults $(n=25-32$ aged 65-88) had significantly higher thresholds than younger adults for salt $(p=0.004)$ and sweet $(p<0.001)$, but not bitter and umami tastes $(n=25-60$, aged 20-40) (Table 1). This contradicts previous findings, which have suggested bitter taste decline and the preservation of sweet perception ${ }^{[8-12]}$.

Ortho- and retro-nasal detection thresholds for two flavour compounds assessed were significantly higher in older adults. 2,5-Dimethyl pyrazine ortho-nasal thresholds were 2.3 times higher in older adults $(p=0.05)$, and retro-nasal thresholds were 3.7 times higher $(p=0.006)$. Dimethyl disulfide detection also increased with age both ortho-nasally by 4.8 times $(p=0.001)$ and retro-nasally by 7 times $(p=0.003)$. However, at suprathreshold levels, ortho-nasal discrimination of caramel flavour and vanillin in skimmed milk was not age dependent, suggesting older adults discriminate flavours above threshold levels easily. These findings agree with previous studies, finding olfactory and flavour perception decline is compound specific ${ }^{[13]}$.

No significant age effects were found for the perception of thickness or mouth-coating in dairy beverages. Older volunteers even exhibited greater sensitivity to mouth-drying than younger adults $(p=0.03)$. These findings suggest that while taste and olfactory acuity can decline with age, texture and suprathreshold flavour perception is not age-dependent. The preservation of texture perception could even cause older adults to place more emphasis on mouth-feel characteristics, when compensating for sensory losses. Hospitals, carehomes and the food industry should take note of sensory preservation with age, especially when targeting foods and beverages towards older adults and patients.

1. BAPEN 2009.

2. Nutrition Action Plan Delivery Board, 2009.

3. Koskinen S \& Tuorila H (2005) Food Quality and Preference 16(5): p. 383-392.

4. Griep MI, Mets TF \& Massart DL (2000) British Journal of Nutrition 83(02): p. 105-113.

5. Koskinen S, Kälviäinen N \& Tuorila H (2003) Appetite 41(1): p. 87-96.

6. Kremer S, Mojet J \& Kroeze JHA (2007) Food Quality and Preference 18(1): p. 106-116.

7. Koskinen S, Nenonen A \& Tuorila H (2005) Physiology \& behavior 85(3): p. 314-323.

8. Spitzer ME (1988) J Gerontol 43(3): p. P71-74.

9. Fukunaga A, Uematsu H \& Sugimoto K (2005) J Gerontol A Biol Sci Med Sci 60(1): p. 109-113.

10. Kaneda H et al. (2000) Chem. Senses 25(3): p. 331-337.

11. Mojet J, Christ-Hazelhof E \& Heidema J (2001) Chemical Senses 26(7): p. 845-860.

12. Murphy C \& Gilmore MM (1989) Perception \& Psychophysics 45(2): p. 121-128.

13. Stevens JC \& Spencer NA (1994) Chem. Senses 19(4): p. 365-369. 